\title{
The role of climatic and anthropogenic stresses on long-term runoff reduction from the Loess Plateau, China
}

\author{
Xiaoming Feng ${ }^{\mathrm{a}}$, Wei Cheng ${ }^{\mathrm{a}, \mathrm{b}}$, Bojie Fu ${ }^{\mathrm{a}, *}$, Yihe Lü ${ }^{\mathrm{a}}$
}

a State Key Laboratory of Urban and Regional Ecology, Research Center for Eco-Environmental Sciences, Chinese Academy of Sciences, Beijing 100085, China

b School of Life Science, University of Science and Technology of China, Hefei, Anhui 230026, China

\section{H I G H L I G H T S}

- River runoff from catchments in the hilly Loess Plateau is in long-term decline.

- Precipitation was the dominant factor causing reduction in river flow.

- Human intervention created transition points in river flow.

- The ecosystem service of water provision decreased after human intervention.
G R A P H I C A L A B S T R A C T

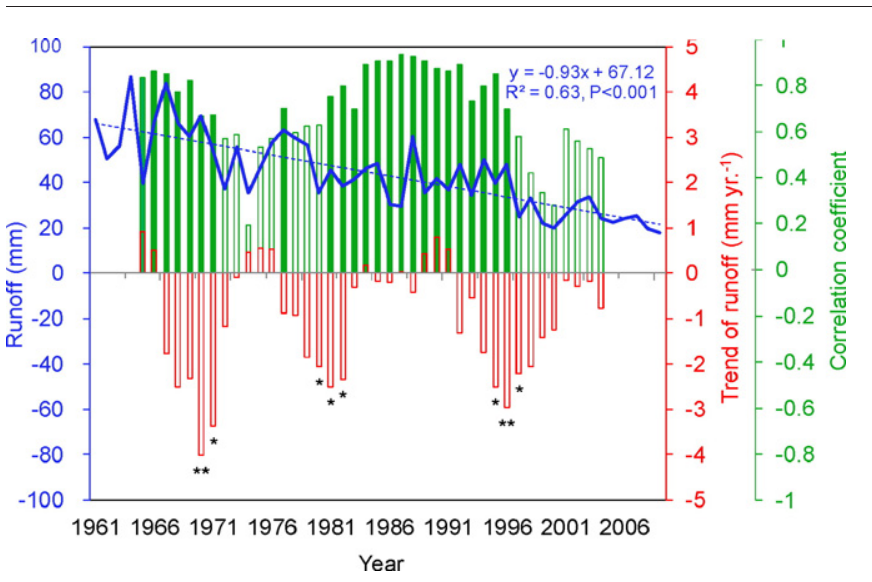

\begin{abstract}
A B S T R A C T
Human intervention has strongly altered patterns of river runoff. Yet, few studies have addressed the complexity and nonlinearity of the anthropogenic stresses on runoff or their interaction with climate. We study the Loess Plateau in China, whose river runoff contributes $65 \%$ of the discharge to the middle reach of the Yellow River; this landscape has been shaped by human activity and is intensively managed. Our purpose is to characterize the interactive roles of climate and human activities in defining river runoff from the Loess Plateau. Applying a transient analysis to discover the time-varying runoff trend and impact factors, we found that the average runoff in the Loess Plateau decreased continuously during the period 1961-2009 (average rate of $-0.9 \mathrm{~mm}$ year ${ }^{-1}$, $P<0.001$ ). This long-term decrease in runoff mainly occurred in three stages, with transitions in 1970, 1981 and 1996. Reduced precipitation was the main reason for the decrease in runoff over the entire study period. However, human intervention played a dominant role in creating the transition points. Water yield (i.e., the ratio of runoff to precipitation) decreased following each anthropogenic transition, causing a 56\% reduction in available freshwater resources during the period 1961-2009. These findings highlight the need for studies that address the dynamic and nonlinear processes controlling the availability of freshwater resources in the light of anthropogenic influences applied under a changing climate. Such studies are essential if we are to meet the human water demand in the Loess Plateau region.
\end{abstract}

(C) 2016 Elsevier B.V. All rights reserved.

\footnotetext{
* Corresponding author at: State Key Lab. of Urban and Regional Ecology, Research Center for Eco-Environmental Sciences, Chinese Academy of Sciences, PO Box 2871, Beijing 100085, China.

E-mail address: bfu@rcees.ac.cn (B. Fu).
} 


\section{Introduction}

River runoff is an important component of the water resources required for human life and economic development (Farley et al., 2005; Wu et al., 2013). Importantly, river flow datasets should not be considered as stationary time series, because both climate change and human activities are driving systematic changes in runoff (Milly et al., 2005). Currently, interest is increasingly focused on analyzing how human activities may shape runoff (Entwisle and Stern, 2005; Chen et al., 2015; Milano et al., 2015); yet in most studies, human activities are simplified and represented as land-use change. The complexity and nonlinearity of runoff change is given little consideration due to a lack of knowledge on the interactive roles of climate change and human activities (Liu et al., 2007). These factors must be included in addressing the security of water supplies and avoiding unforeseen changes.

Human activity in the Loess Plateau region of northern China (see location in Fig. 1a) has a long and complicated history with $>1000$ years of human settlement (Shi et al., 2002; Syvitski and Kettner, 2011). Yet, particularly over the past five decades, intensive human activity with the primary purpose of alleviating severe top-soil erosion, has shaped the ecosystem services (ES, i.e., benefits people obtain from ecosystems, Millennium Ecosystem Assessment, 2005; Carpenter et al., 2006) provided by catchments in the Loess Plateau (Mu et al., 2007). Since the 1950 s, a number of soil conservation measures, such as constructing terraces and sediment-trap dams, have been implemented in the Loess Plateau. These have been characterized as engineering methods related to soil conservation (Zhang et al., 2008). Furthermore, in late 1999, China implemented a massive revegetation program in the name of ecological restoration that involved returning croplands on steep slopes $\left(>25^{\circ}\right)$ back to woodland, shrub land or grassland $(\mathrm{Xu}$ et al., 2002).

Efforts to reduce soil erosion are critical to maintaining environmental quality. However, various studies have reported that a reduction in river runoff occurred as an outcome of the enhanced soil conservation in the Loess Plateau (Li et al., 2009; Gao et al., 2015; Wei et al., 2015; Liang et al., 2015). River runoff from the Loess Plateau contributes to the tributaries of the Yellow River; therefore, a reduction in runoff from the plateau will not only influence the provisioning of water for local residents, but will also affect the downstream flow in the Yellow River (Tang et al., 2008). Understanding the effects of soil conservation measures on river runoff from the Loess Plateau is important for guiding the implementation of future soil conservation initiatives (Xu et al., 2004). However, it is difficult to draw generally applicable conclusions based on current studies, which generalize different soil conservation measures (i.e. constructing terraces, sediment-trap dams, revegetation) as a vague concept of human intervention to river flow. For example, a change-point around 1983 was detected in the runoff from the Huangfu catchment, which has been monitored since the 1950s (Zhang et al., 2008; Zuo et al., 2016). Zhang et al. (2008) concluded that the anthropogenic factor behind the change was the construction of sediment-trapping dams and reservoirs; but in contrast, Zuo et al. (2016) concluded that it was due to revegetation. In fact, the effect of human intervention on river runoff may vary both in the details of the soil conservation measures and their efficiency, which could be partially reflected in the most recent attribution analysis on sediment reduction in the Loess Plateau (Wang et al., 2015). In current analyses of the effects of human (a)

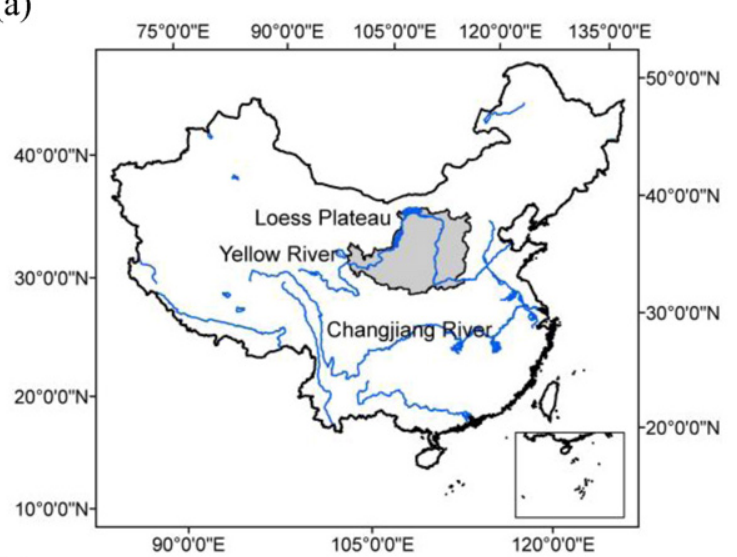

(c)

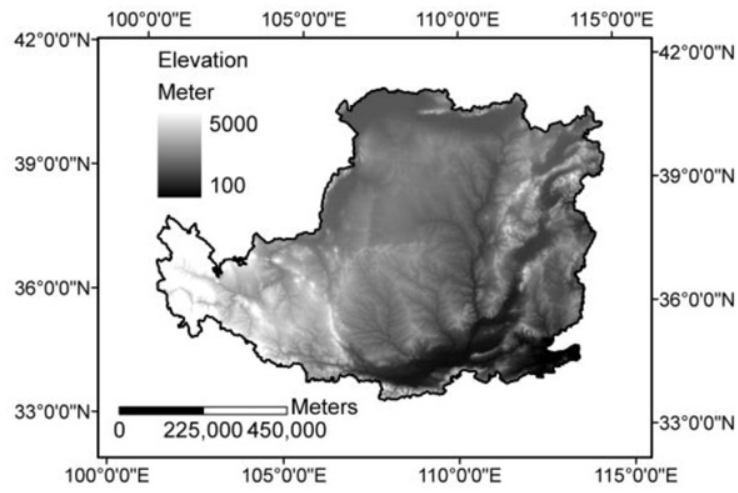

(b)

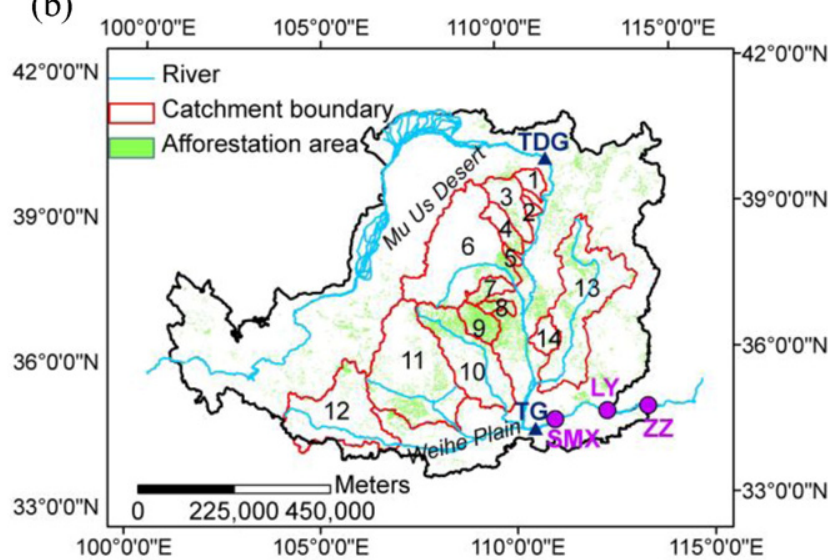

(d)

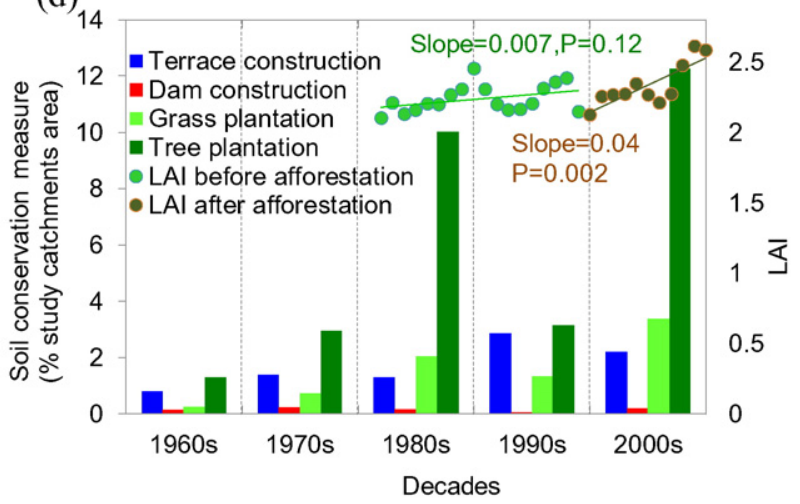

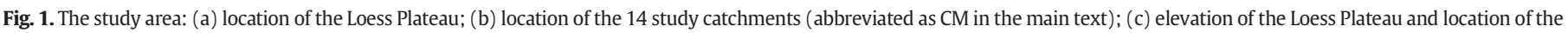

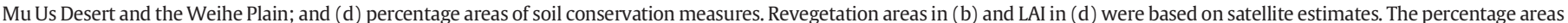

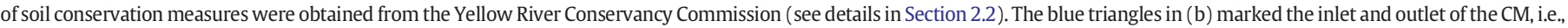

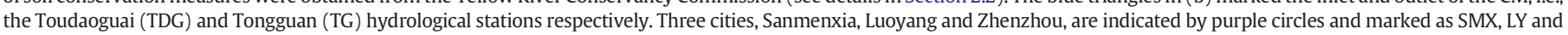
$\mathrm{ZZ}$, respectively. These three cities rely directly on the ecosystem service of water supply provided by the CM. 
Table 1

Catchment characteristics and hydrological data for the study period 1961-2009.

\begin{tabular}{|c|c|c|c|c|c|c|c|}
\hline ID & Catchment name & Gauging station name & Area $\left(\mathrm{km}^{2}\right)$ & Elevation(m) & PPT $\left(\mathrm{mm}\right.$ year $\left.^{-1}\right)$ & PET $\left(\mathrm{mm}\right.$ year $\left.^{-1}\right)$ & Runoff (mm year ${ }^{-1}$ ) \\
\hline 1 & Huangfu & Huangfu & 3230 & 1162 & 406 & 1026 & 37 \\
\hline 2 & Gushan & Gaoshiya & 1260 & 1167 & 410 & 1047 & 50 \\
\hline 3 & Kuye & Wenjiachuan & 8621 & 1263 & 402 & 1075 & 60 \\
\hline 4 & Tuwei & Gaojiachuan & 3307 & 1215 & 411 & 1093 & 89 \\
\hline 5 & Jialu & Shenjiawan & 1138 & 1117 & 437 & 1093 & 48 \\
\hline 6 & Wuding & Dingjiagou & 24,682 & 1325 & 373 & 1133 & 35 \\
\hline 7 & Dali & Suide & 3861 & 1202 & 484 & 1110 & 37 \\
\hline 8 & Qingjian & Yanchuan & 3600 & 1186 & 499 & 1084 & 38 \\
\hline 9 & Yanhe & Ganguyi & 5857 & 1282 & 506 & 1072 & 34 \\
\hline 10 & Beiluo & Zhuangtou & 25,723 & 1283 & 502 & 1049 & 35 \\
\hline 11 & Jinghe & Zhangjiashan & 43,106 & 1420 & 527 & 1000 & 33 \\
\hline 12 & Weihe & Linjiacun & 30,122 & 1895 & 502 & 1015 & 65 \\
\hline 13 & Fenhe & Hejin & 38,728 & 1135 & 515 & 1004 & 23 \\
\hline 14 & Xinshui & Daning & 4186 & 1217 & 502 & 1009 & 29 \\
\hline
\end{tabular}

ID, catchment identification number; PET, potential evapotranspiration; PPT, annual precipitation.

interventions on river runoff from the Loess Plateau the interventions are often treated as static although they may have been implemented over long periods. Moreover, the interactions of human-generated effects with climatic factors are not included in current analyses (Zhang et al., 2008; Villa et al., 2014; Zhao et al., 2014). Empirical evidence strongly indicates that climatic and anthropogenic factors interact with one another, often in a nonlinear fashion, varying in time and creating new patterns of ecosystem behavior (Agrawal and Lemos, 2007; Liu et al., 2007; Chen et al., 2015). Thus, an analysis of the complex nature of water resource provision in intensively managed ecosystems (like the Loess Plateau) is urgently needed.

This article investigates the complexity of human activities in shaping river runoff in the Loess Plateau under a changing climate during 1961-2009. The objectives are to 1) explore the non-linearity of runoff trends; 2 ) identify the roles of human soil conservation measures in runoff trends and their interaction with climate factors; 3 ) investigate changes in the ES of freshwater provisioning by catchments in the Loess Plateau; and to discuss the differences between the time-varying and the static runoff change as well as the particular meanings of this study as they are related to water resources management under climatic and anthropogenic stressors.

\section{Study area and datasets}

\subsection{Study area}

Our study area is the fourteen catchments, which comprise the main watershed area of the Loess Plateau (named CM hereafter, Fig. 1a). River runoff from these 14 catchments (about 35\% of the Loess Plateau area) contributes $65 \%$ of the discharge into the middle reach of the Yellow River (Fig. 1b, and Fig. 3). The annual average precipitation is $\sim 450 \mathrm{~mm}$ (Table 1). Precipitation is the only water input into the ecosystem of the CM. With the Mu Us Desert in the northwest and the Weihe Plain in the southeast, the study area lies in the hilliest area of the Loess Plateau region, with an average elevation of $1400 \mathrm{~m}$. It is characterized by an intensely dissected landscape with gully densities varying in length from 2 to $8 \mathrm{~km} \mathrm{~km}^{-2}$ (Wang et al., 2007). The topography, together with the erodible, wind-deposited loess soil, sparse vegetation and intense summer rainfall make the $\mathrm{CM}$ the predominant sediment source, comprising $90 \%$ of the soil erosion of the Loess Plateau (Rustomji et al., 2008). It is also an area of concentrated and developed check-dams and terraces that accounts for $>85 \%$ of the entire Loess Plateau both in area and number (Ministry of Water Resources, 2013). In addition, satellite data have revealed that $>80 \%$ of the area of revegetation of the entire Loess Plateau lies within the CM (Fig. 1a). The satelliteestimated revegetation area was extracted from Landsat TM/ETM (spatial resolution $30 \mathrm{~m}$ ). It is taken as the area subjected to land-cover changes between year 2000 and 2008.

During the period 1961-2009, annual average temperature in the CM increased significantly (at a rate of $0.034{ }^{\circ} \mathrm{C}$ year ${ }^{-1}, P<0.001$; Fig. 2). Annual precipitation (PPT) decreased slightly (at a rate of $-1.42 \mathrm{~mm}_{\text {year }}{ }^{-1}$, $P=0.08$ ). However, the change in potential evapotranspiration (PET) is insignificant $(P=0.26$; Fig. 2$)$. This insignificant PET trend results from contributions from other environmental factors, including net radiation, wind speed and relative humidity; a thorough analysis has been conducted by Liu and McVicar (2012). The CM is water-limited, with the dryness index PET/PPT being $2.4 \pm 0.5$ during 1961-2009. Ecosystems in the CM rely heavily on water availability (Piñol et al., 1999).

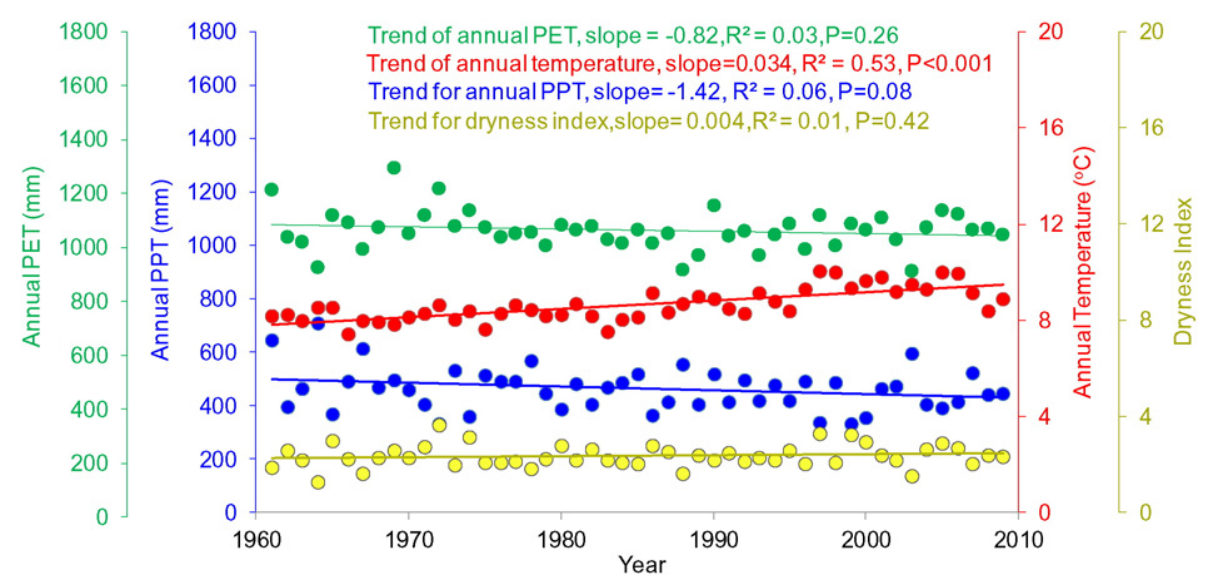

Fig. 2. Trend of annual temperature, potential evapotranspiration (PET), precipitation (PPT) and the dryness index (PET/PPT) for the CM from 1961 to 2009. 

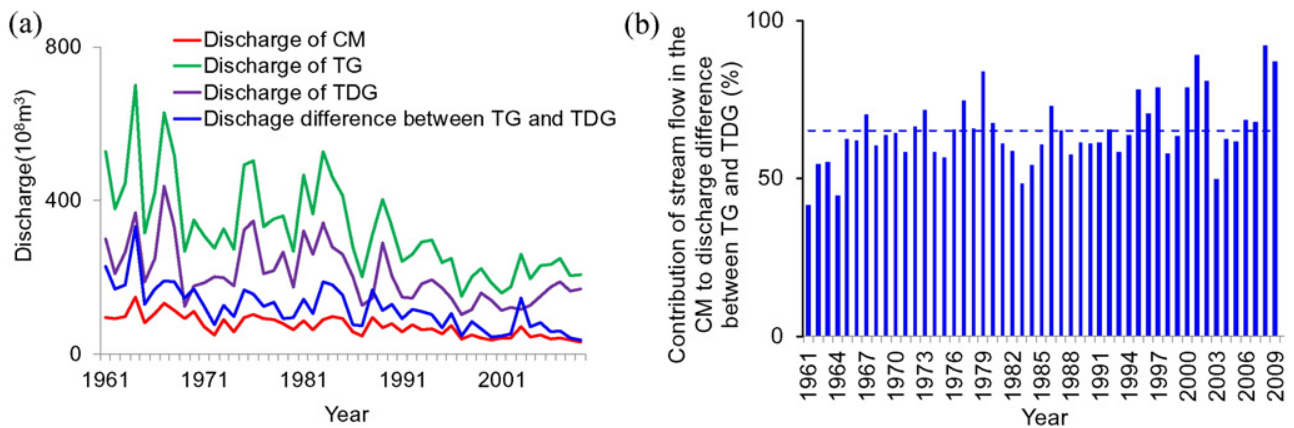

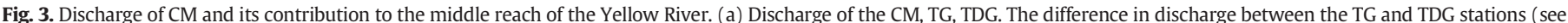

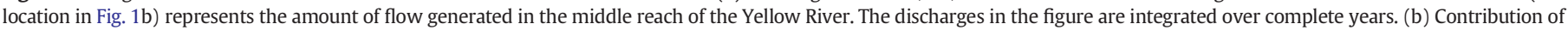
river flow from the $\mathrm{CM}$ to flow generated in the middle reach of the Yellow River. The dotted line shows the average value of the contribution.

The development of soil conservation measures and related engineering varied with time. Terrace construction peaked in the 1990s ( $2.9 \%$ of the $\mathrm{CM}$ ); however, terraces served as an important soil conservation measure in the 1960 s- 1970 s (32\% and $26 \%$ of soil conservation area of the CM in the 1960s and 1970s, respectively). Revegetation began in 1999, with both grass and tree plantation peaking in the 2000 s (3.1\% and $12.2 \%$ of the CM, respectively). Dam construction occupied the smallest area of the $\mathrm{CM}(0.003-0.2 \%)$, while tree planting occupied the largest area (1.3-12.2\%). Note that soil conservation measures other than terrace construction decreased sharply in the 1990s (annual terrace construction, tree planting, and pasture development was 0.15 , 10.0 and $1.3 \%$ of the CM respectively in the 1980 s, but reduced to $0.002 \%, 3.1 \%$ and $1.3 \%$ in the $1990 \mathrm{~s}$ ). Furthermore, tree and grass plantation prior to 1999 did not cause a statistically significant change in the leaf area index $(\mathrm{LAI})$ in the $\mathrm{CM}$ ( slope $=0.007, P=0.12$ ). The significant LAI increase (slope $=0.04, P=0.002$ ) occurred as a result of the massive revegetation after 2000 (Fig. 1d).

\subsection{Datasets}

Using data from 1961 to 2009, river runoff from the 14 individual catchments were obtained from the Water Resources Committee of the Yellow River Conservancy Commission. Daily average records of flow volumes $\left(\mathrm{SV}, \mathrm{m}^{3} \mathrm{~s}^{-1}\right)$ were converted to annual runoff depth $\left(S D, \mathrm{~mm}_{\text {year }}{ }^{-1}\right.$ ) for each component catchment in the CM using Eq. (1) (Feng et al., 2012):

$S D=\frac{\sum_{i=1}^{n} S V_{i} \times 60 \times 60 \times 24}{1000 \times A}$

where, $A$ is the area of each individual catchment $\left(\mathrm{km}^{2}\right)$, and $n$ is 365 for a normal year, or 366 for a leap-year.

The State Meteorology Bureau provided daily precipitation, temperature and meteorological data including net radiation, wind speed and relative humidity. The daily meteorological maps were interpolated from isolated stations. Using the ANUSPLIN program, the point climate data passing the continuity test (i.e. data quality check to make sure the data contain consecutive months in the correct sequence) are interpolated with an algorithm using the thin-plate smoothing spline method. This interpolation method estimates exact fields of climatic variables by including the linear covariates rather than a constant lapse rate to represent the effect of elevation on climate (Wahba and Wendelberger, 1980; Feng et al., 2012). $>80 \%$ of the total 172 individual stations were used for each interpolation. The daily maps were further summed to give annual maps. Potential evapotranspiration (PET) is used as a climate index combining air temperature, net radiation and wind speed (Liu and McVicar, 2012). PET is widely used to partition precipitation into runoff and evapotranspiration under worldwide climate change, including the Loess Plateau (Woodward et al., 2014; Zhou et al., 2015; Liang et al., 2015). In this study, monthly PET was estimated using the Penman method (Penman, 1948), then accumulated to give annual totals.

Areas of terracing and sediment-trap dam construction, as well as tree and the natural growth of pasture, within each catchment from the 1960s, through to the 2000s were obtained from the Yellow River Conservancy Commission (http://tghl.forestry.gov.cn/). The time-step of the data is ten years.

Land-cover data for 2000 and 2008 were extracted from Landsat satellite data (spatial resolution $30 \mathrm{~m}$ ). Revegetation area was defined as land-cover change from cropland in 1990s to woodland, shrub land or grassland in 2000s. It was derived by overlay analysis of the 2000 and 2008 land-cover maps. Because the earliest satellite estimates of the Normalized Difference Vegetation Index (NDVI, spatial resolution $1 \mathrm{~km}$ ) were available in 1982, LAI derived from the Global Land Surface Satellite (GLASS) NDVI series (spatial resolution $1 \mathrm{~km}$, Zhao et al., 2013; www.landcover.org) was used to indicate varied growth conditions and plant structure in the period of 1982-2009. Details on the relationship between NDVI and LAI are given by Feng et al. (2012). Total revegetation area and averaged LAI were used to represent satellite estimation of land-cover change for each catchment.

\section{Methods}

\subsection{Runoff trend}

Runoff trend was calculated by linear regression of averaged runoff from the $\mathrm{CM}$ against time. Two parameters (i.e., slope of the regression and its significance tested by least squares method) derived from the regression are important. The slope of the estimated linear relationship was used to indicate the general trend in runoff $\left(\mathrm{mm}\right.$ year ${ }^{-1}$ ) over the study period of 1961-2009. The significance level was used to indicate the statistical significance of the trend. Trends with a significance level $<95 \%$ $(P<0.05)$ were taken as statistically significant. Aside from the general trend of runoff, a transition analysis was conducted with a moving time window. The window-by-window regression coefficient shows the temporal variability of runoff trend. A 10-year moving window was selected to ensure the detection of the change caused by the temporally variable soil conservation measures using a 10-year step, and to avoid the few degrees of freedom caused by data overlapping in neighboring time windows.

\subsection{Role of climatic and anthropogenic factors}

Aligned with the runoff trend analysis, both the effects of general climate change over the period of 1961-2009 and the climate variation signal in runoff were calculated, with the latter compiled over a 10year moving window. The time series of annual precipitation, PET and runoff were detrended before correlation analysis. The partial correlation method was used to isolate the impact of climatic changes from that of other factors causing runoff change. The need to diagnose the correlation between two signals while eliminating the influence of 
other signals in a complex system has led to the partial correlation method being used in fields containing a large number of interactions, such as ecology and climatology (Yuan et al., 2015; Zhou and Miller, 2000). The partial correlation coefficient is calculated as

$r_{i j, k}=\frac{r_{i j}-r_{i k} r_{j k}}{\sqrt{\left(1-r_{i k}^{2}\right)\left(1-r_{j k}^{2}\right)}}$

where $r_{i j}, r_{i k}$ and $r_{j k}$ are correlation coefficients between two variables (for example, climatic factor and runoff in this study), and $r_{i j, k}$ is the partial correlation coefficient between variable $i$ and $j$, with the effect of variable $k$ removed (Hald, 1952; Piao et al., 2014). In comparing the responses of annual runoff variations, partial correlation analysis of the ratios of runoff to annual PET and to precipitation provides the correlation between fluctuations in runoff and those in each of the factors influencing runoff, while controlling other factors.

For the period when a significant impact of climate has disappeared, multiple regression analysis was conducted to determine the contribution of anthropogenic influences to runoff trends over the CM catchments.

The multiple regression model is expressed as

$\Delta S=\beta_{0}+\beta_{1} x_{1}+\beta_{2} x_{2}+\ldots+\beta_{n} x_{n}+\ell_{i}$

where $\Delta S$ is change in runoff. $\beta_{0}$ is the intercept, and $\beta_{1}, \beta_{2}, \ldots . \beta_{\mathrm{n}}$ are the coefficients of impact factors $x_{1}, x_{2}, \ldots x_{n}$ respectively; $\ell_{i}$ is the error term. In this study, we included terrace and dam construction, tree and grass plantation, satellite-derived revegetation area and changes in LAI, annual PPT and annual PET as the potential impact factors. Satellite-derived revegetation area and LAI represent the parts of the tree and grass plantations that can be remotely sensed at a spatial resolution of $30 \mathrm{~m}$ and $1 \mathrm{~km}$, respectively. The normalities of the factors have been tested before a step-wise method of regression was applied using SAS software. The final impact factors are those passing the significance test $(P<0.05)$ during the interactive model regression analysis of the $\mathrm{CM}$ records. Runoff trend analysis and partial correlation analysis were applied for both the overall $\mathrm{CM}$ and each catchment independently. Data from the 14 catchments are combined for generating the multiple regression relationship in Eq. (3) representing the CM.

For comparison, we also used Pettitt's (1979) method to detect change-points in the runoff from the CM. This method detects a significant $(P<0.05)$ but static change-point in the mean of a time series. It has been widely used in discovering change points of runoff and sediment discharge in the Loess Plateau (refer to Mu et al., 2007; Zhang et al., 2008; Zhao et al., 2014 for details of the method).

\subsection{Change in the ecosystem service of water provision}

The ES of water provision was represented by water yield, which is the ratio of runoff to precipitation. A double mass curve of precipitation vs. runoff was used to detect changes in water yield resulting from anthropogenic intervention before and after the transition years. According to Searcy and Hardisoni (1960), the accumulation of annual runoff against the accumulation of annual precipitation during the same period will appear as a straight line plot as long as the data are proportional. Thus, a break in the slope of the double-mass curve of precipitation vs. river

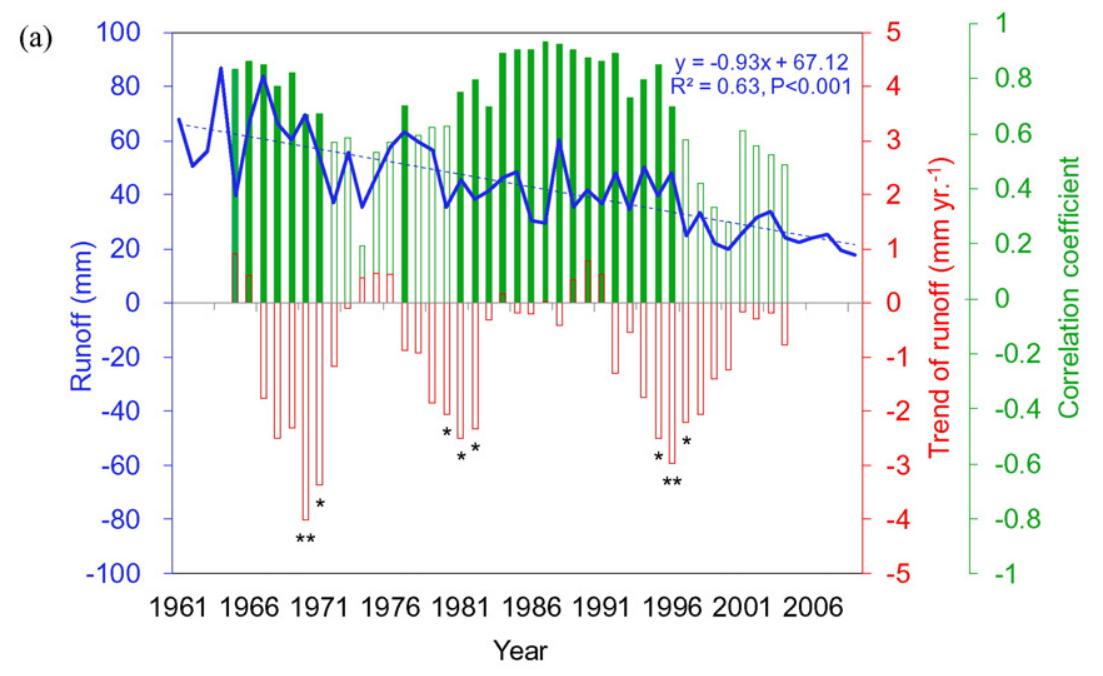

(b)

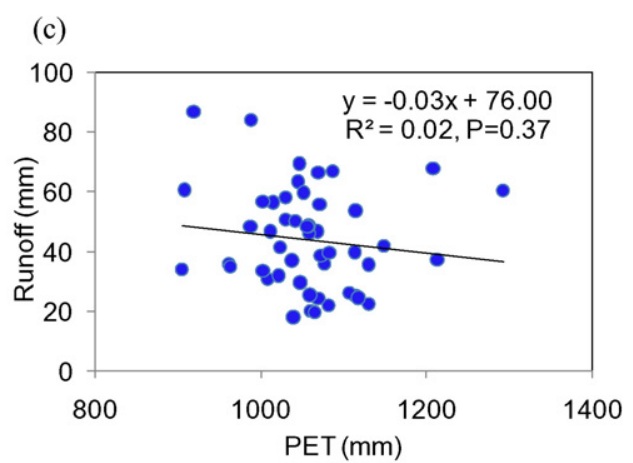

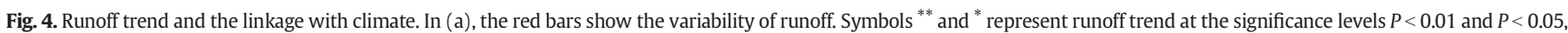

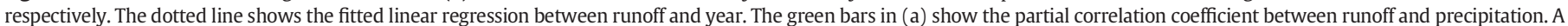

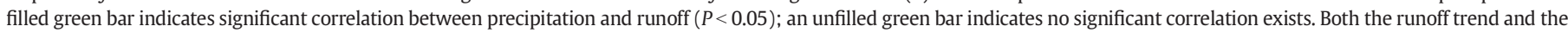

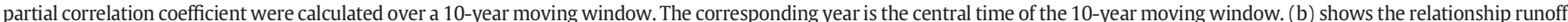

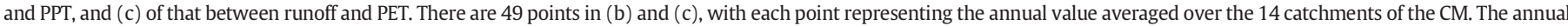

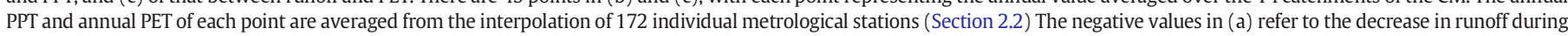
the study period. 
flow means a change in water yield. The corresponding year of the breaks in the slope gives the time at which a change in water yield occurred.

\section{Results}

\subsection{Runoff change from 1961 to 1999}

River runoff decreased in a non-linear fashion at an average rate of

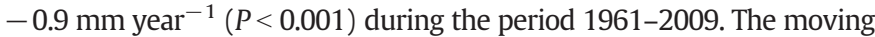
window detected three stages of significant decrease $(P<0.05)$ in runoff with 1970, 1981 and 1996 as the transition years. The rates were -4.0 ,
-2.5 and -3.0 mm year $^{-1}$ in the periods 1966-1975, 1977-1986 and 1992-2001, respectively. For other periods, the runoff decrease tended to be insignificant. Thus we conclude that the long term decrease in runoff in the CM mainly occurred in three stages: from 1960 to 1970, from 1977 to 1982 and from 1992 to 2000 . Runoff remained rather stable in the periods of 1970-1976 and 1980-1990 (Fig. 4a).

\subsection{Roles of climatic and anthropogenic stresses on runoff reduction}

For the entire period of 1961-2009, the interannual variation of runoff was significantly correlated with the corresponding annual PPT

Table 2

Anthropogenic factors of runoff change in different stages.

\begin{tabular}{|c|c|c|c|c|}
\hline & 1960s vs. 1970 s & 1970 s vs. 1980 s & 1980s vs. 1990 s & 1990 s vs. 2000 s \\
\hline$\Delta$ Terra $(\%)$ & 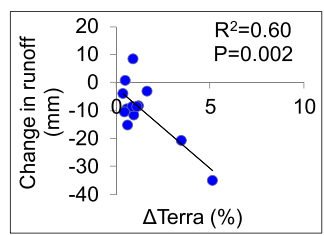 & 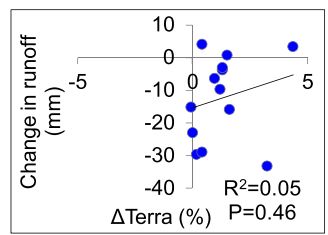 & 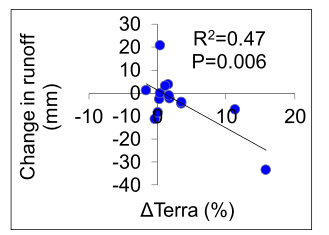 & 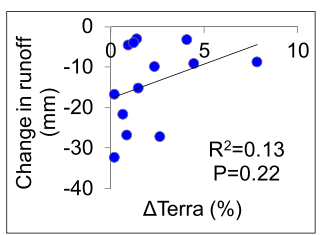 \\
\hline$\Delta \operatorname{Dam}(\%)$ & 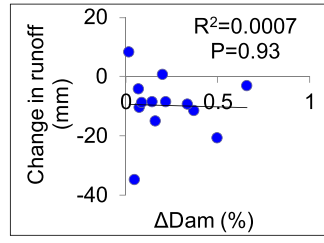 & 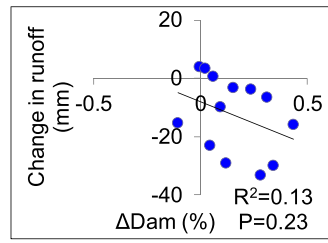 & 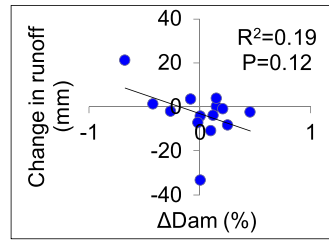 & $\underset{\substack{R^{2}=0.22 \\
P=0.10}}{(\%)}$ \\
\hline$\Delta$ Tree $(\%)$ & 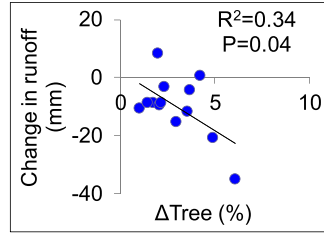 & 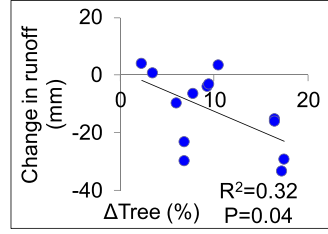 & 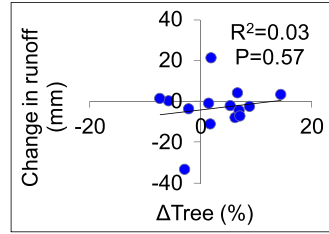 & 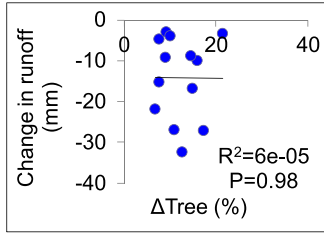 \\
\hline$\Delta$ Pasture (\%) & 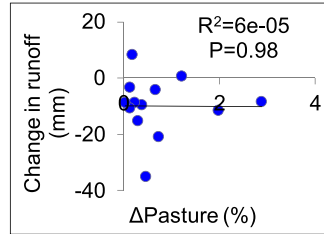 & 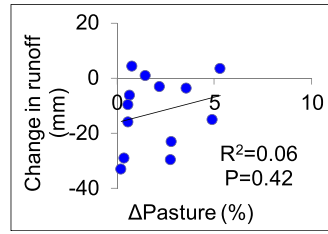 & 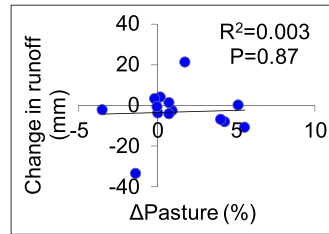 & 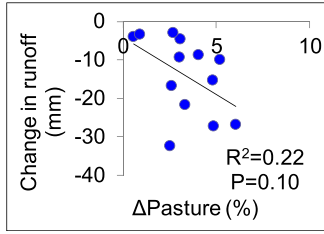 \\
\hline$\Delta \mathrm{LAI}$ & NULL & NULL & 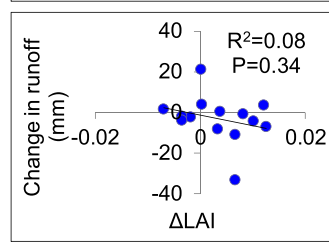 & 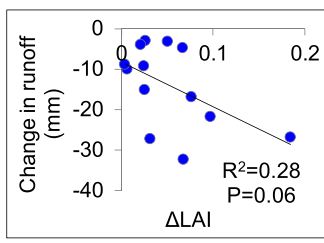 \\
\hline RS_AFFOR (\%) & NULL & NULL & NULL & 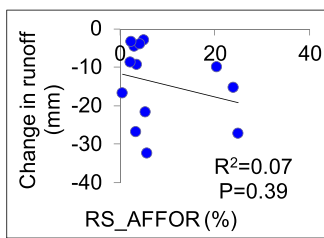 \\
\hline$\triangle \mathrm{LAI} \times \mathrm{RS} \_$AFFOR & NULL & NULL & NULL & 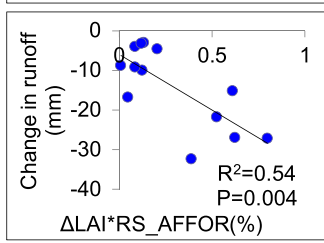 \\
\hline
\end{tabular}

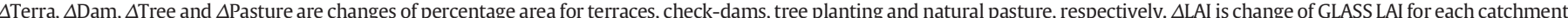

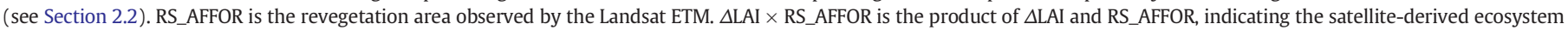
change. $\triangle \mathrm{PPT}$ is the change in annual precipitation between the two compared periods.

NULL indicates that the variable was not included in modeling the runoff change. 
Table 3

The regression models of runoff change in different stages.

\begin{tabular}{lll}
\hline Period & Regression model & \\
\hline 1960s vs. 1970s & $\mathrm{Y}=-1.86-5.79 \times \Delta$ Terra & $\mathrm{R}^{2}=0.60$ \\
1970s vs. 1980s & $\mathrm{Y}=-8.47+0.35 \times \Delta$ PPT & $\mathrm{R}^{2}=0.39$ \\
1980s vs. 1990s & $\mathrm{Y}=1.44-1.65 \times \Delta$ Terra & $\mathrm{R}^{2}=0.47$ \\
1990s vs. 2000s & $\mathrm{Y}=-10.08+0.20 \times \Delta$ PPT $-22.39 \times \Delta$ LAI $\times$ & $\mathrm{R}^{2}=0.74$ \\
& RS_AFFOR & \\
\hline
\end{tabular}

$\Delta$ Terra, $\triangle$ LAI $\times$ RS_AFFOR are same as those in Table 2. $\triangle$ PPT is change of annual precipitation.

$\left(R^{2}=0.43, P<0.001\right.$, Fig. 4b), but not with annual PET $\left(R^{2}=0.02, P=\right.$ 0.37 , Fig. $4 c$ ), indicating a direct hydrological response of the CM ecosystem to variations in precipitation. This finding is consistent with the fact that the Loess Plateau is a water-limited region and has a dryness index PET/PPT of $2.4 \pm 0.5$. Moreover, the dryness index remained stable from 1961 to $2009(P=0.42)$.

However, our partial analysis with a 10-year moving window further found a temporally varying correlation between runoff and PPT $\left(r_{\text {SF_PPT }}\right)$ during 1961-2009. The correlation $r_{\text {SF_PPT }}$ was significant $(P<0.01)$ over the 1960s, and in some years during the 1970s (e.g., 1976), as well as during the period from 1980 to 1996. A weakened $r_{\text {SF_PPT }}$ was detected following the runoff decrease (from $0.70(P=$ $0.04)$ to $0.59(P=0.09)$; and from $0.72(P=0.03)$ to $0.60(P=0.09)$ when the central time of the 10-year window moved away from 1970 and 1996), indicating human intervention had affected runoff. Moreover, the human intervention derived $r_{\mathrm{SF} \text { PPT }}$ to be insignificant $\left(P>0.05\right.$; Fig. 4a). However, the decreased and insignificant $r_{\mathrm{SF}_{-} \mathrm{PPT}}$ in the 1970s returned to being significant again over the period 1980$1990(0.73(P=0.03)$ in 1976; 0.89-0.92 $(P<0.001)$ in 1984-1991), indicating a re-stabilized hydrological response of runoff to variations in precipitation within the ecosystem. Compared to the other two stages, around 1981, the higher $r_{\text {SF_PPT }}$ and the shorter period of decrease in $r_{\text {SF_PPT }}$ indicate the weaker effects of human intervention on runoff change. The $r_{\text {SF_PPT }}$ decreased abruptly in the beginning of the 2000s, from $0.64(P=0.07)$ and to $0.58(P=0.10)$, indicating an intensive human intervention affecting runoff in this period.

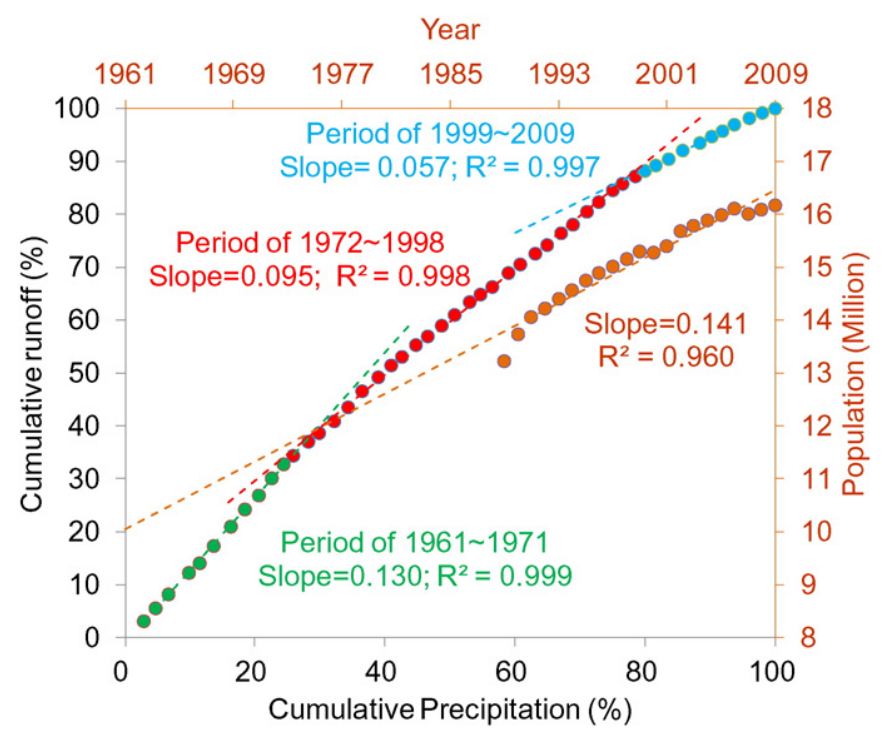

Fig. 5. Change of runoff ratio in different stages (green, red and blue dots indicate runoff in the periods 1961-1971, 1972-1998 and 1999-2009, respectively) and the increase in population of the main cities of the middle reach of the Yellow River (Sanmenxia, Luoyang and Zhengzhou) reported by the Statistical Yearbook (yellow dot, Henan Statistical Bureau, http://www.ha.stats.gov.cn/). Precipitation and runoff are accumulated as percentages of the total values during the study period 1961-2009.
The temporally varying effect of climate in shaping runoff in the $\mathrm{CM}$ over time indicates that anthropogenic factors caused the reduction in runoff, especially during the period of the insignificant $r_{\mathrm{SF} \_ \text {PPT. }}$. Our analysis further defined the anthropogenic reasons for the runoff decrease: terrace construction was a significant human factor reducing runoff from the 1960s to the 1970 s $(P=0.002)$ and tree plantation and terrace construction are highly correlated in this period (correlation coefficient $0.71, P=0.007)$. No anthropogenic factors acted to decrease runoff from the 1970 s to 1980 s-1990s or from the 1980s-1990s to the 2000s. Instead, tree plantation impacted runoff from 1970s to $1980 \mathrm{~s}$ $(P=0.04)$. Terrace construction triggered runoff reduction $(P=$ 0.006 ) from 1980s to 1990s. Revegetation played an important role in the runoff reduction $(P=0.004)$ after the year 1999; this role was indicated by satellite estimation of variations in LAI and revegetation area (Table 2). Moreover, the regression modeling shows that the effect of tree plantation in causing the runoff decrease from 1970s to $1980 \mathrm{~s}$ was concealed by that of the varied precipitation $(P=0.02$, Table 3$)$.
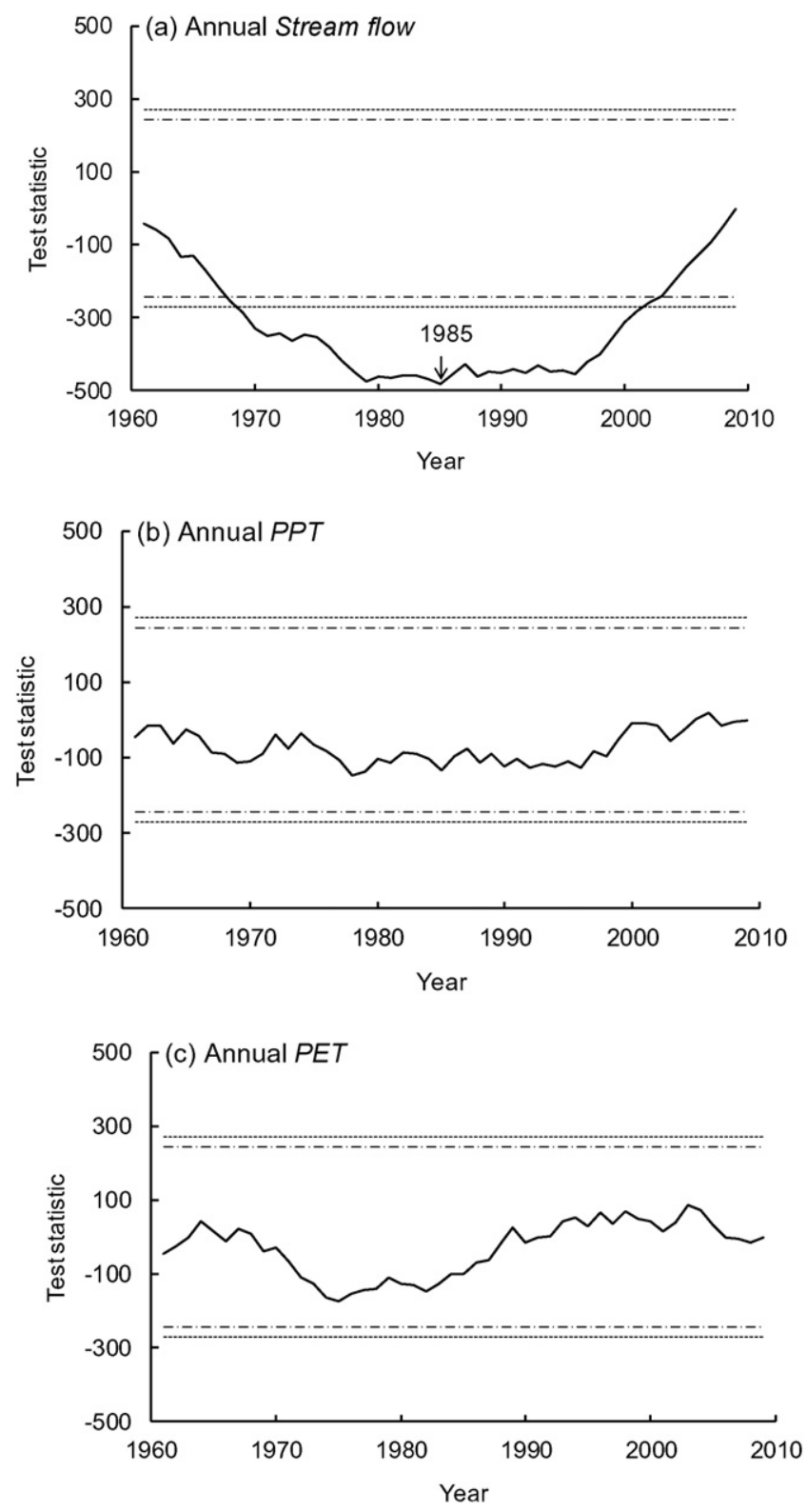

Fig. 6. Pettitt's test K statistic used for detecting a change-point in (a) annual runoff; (b) annual precipitation and (c) annual potential evapotranspiration for the CM. The horizontal lines in each graph represent the critical values of $5 \%$ (dotted) and $10 \%$ (solid). When a minimum or maximum in the value of $\mathrm{K}$ statistic occurs outside these lines, it indicates the timing of a statistically significant change-point. 


\subsection{Altered ecosystem service of water provision due to runoff reduction}

A reduced water yield following the anthropogenic transition years can be detected. On average, before $197013 \%$ of precipitation was converted to runoff. During the periods 1971-1998 and 1999-2009, 9.5\% and $5.7 \%$ of precipitation was converted to runoff, respectively (Fig. 5). This change in water yield implies the amount of freshwater available for recharging runoff in the 2000s declined by $56 \%$ compared to the 1960 s, given the same precipitation input in the CM. Sanmenxia, Luoyang, and Zhengzhou are the nearest main cities downstream along the main stream of the Yellow River, and they rely directly on the ES for water provisioning provided by the $\mathrm{CM}$ (see Fig. 1a for the locations of these cities), The Statistical Yearbook reports that the population of these cities increased at a rate of 0.14 $\mathrm{M}$ year $^{-1}$ during 1989-2009 (http://www.ha.stats.gov.cn). We conclude that the per capita freshwater resource declined by $74 \%$ in the 2000 s compared to 1960 s, given the unchanged precipitation input and the population increase (Fig. 5).

\subsection{The difference between the time-varying and the static runoff change}

Pettitt's method divided the time series of runoff into two sub-series. The change-point of runoff in the CM during 1961-2009 was the year
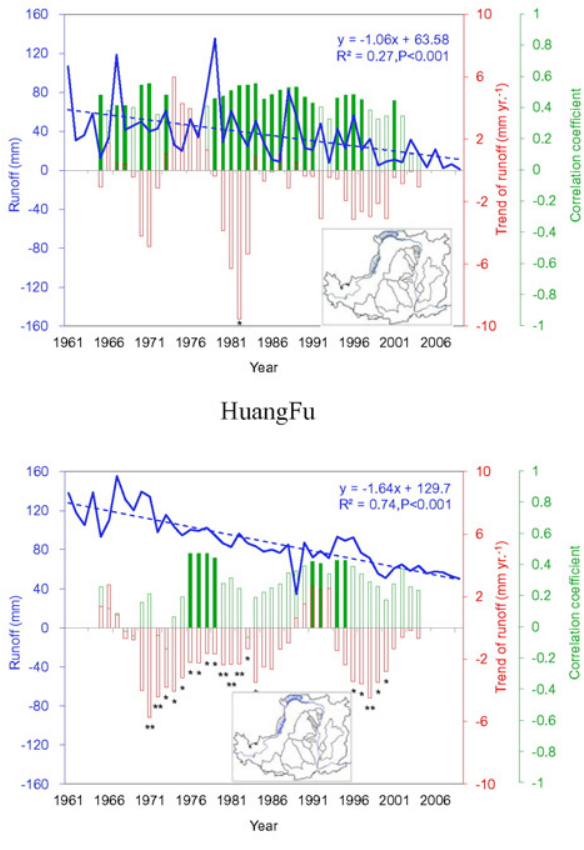

TuWei

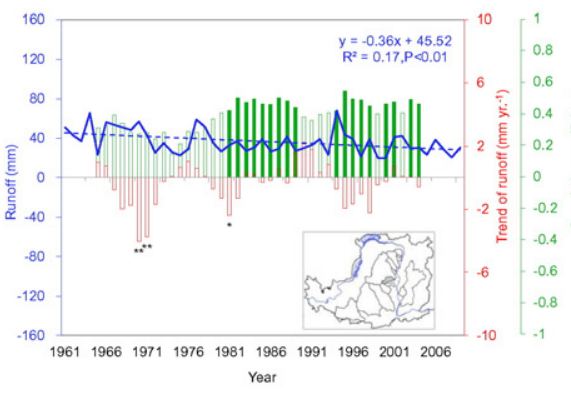

$\mathrm{DaLi}$

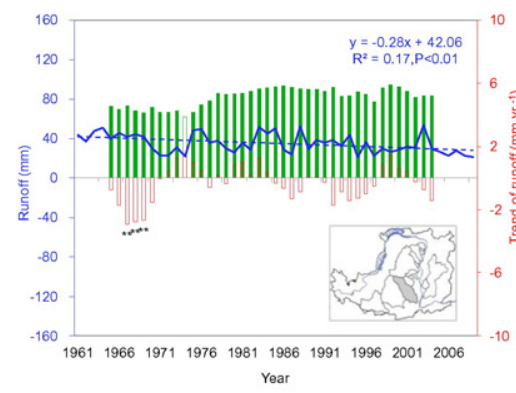

BeiLuo
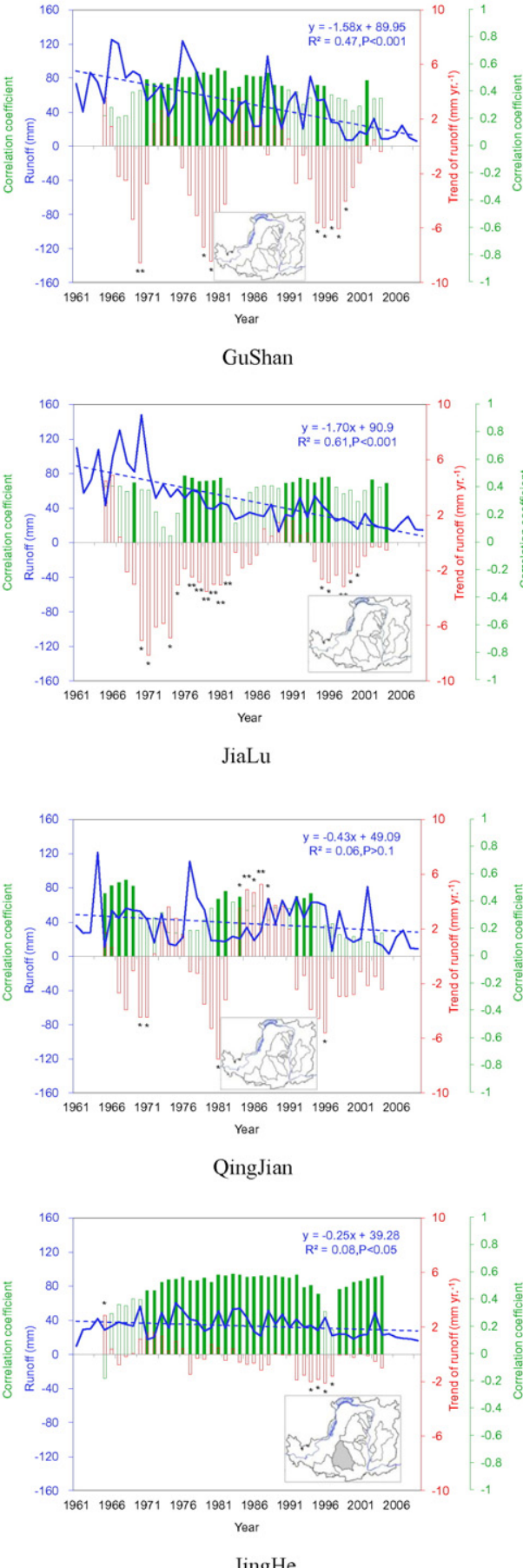
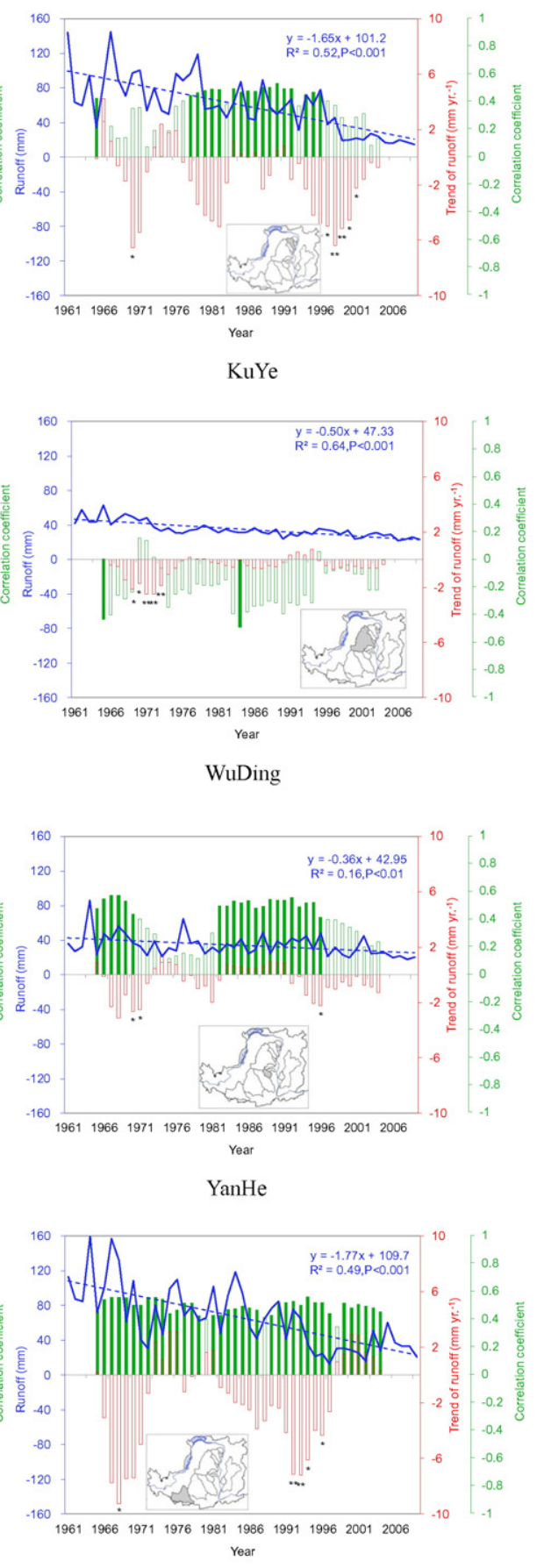

WeiHe

Fig. 7. Runoff trend and the linkage with climate same as Fig. 4a but for the separate catchments, with the location shown in the inset. 


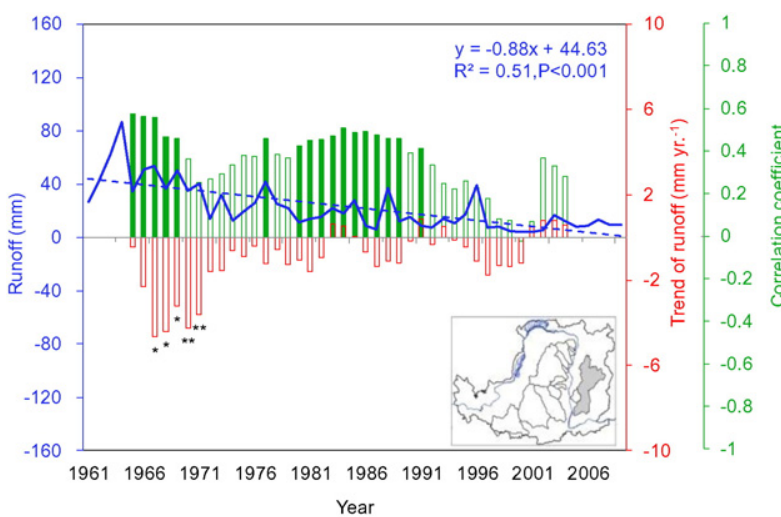

FenHe

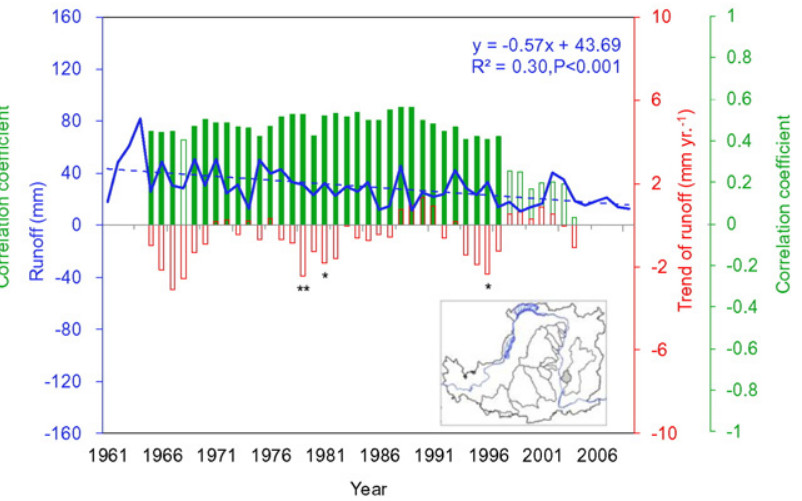

XinShui

Fig. 7 (continued).

1985. This change-point must have been anthropogenically caused because neither a corresponding change of annual precipitation nor a change in annual PET was detected (Fig. 6). We have also shown that the anthropogenic stress occurs separately for the different measures: the combination of terrace and dam construction as a rapidly introduced engineering measure, against tree and pasture plantation which was gradually introduced before and after 1985 . However our analysis found no soil conservation measures that can explain the runoff change before and after the year 1985. It probably occurred because the soil conservation measures were highly integrated in periods before and after the change-point detected by Pettitt's method, making it difficult to clarify, and hence difficult to isolate the different effects from each other.

\subsection{The spatial variability between catchments}

Our analysis has revealed a general picture of the interactive roles of climatic and anthropogenic stresses in long-term runoff reduction in the loess hilly area. However, spatial variations cannot be ignored for different catchments (Fig. 7). River flow in all the catchments included significantly decreased during the study period; however, the magnitude of runoff reduction varied (the lowest value of $-0.25 \mathrm{~mm}$ year $^{-1}(P=$ $0.05)$ in the Jinghe catchment, the highest value of $-1.77 \mathrm{~mm}$ year $^{-1}$ $(P<0.01)$ in the Weihe catchment). Less than three change-points could be detected in catchments other than Gushan, Tuwei, Jialu and Qingjian. In an opposite trend, a significant runoff increase $(P<0.01)$ occurred in Qingjian catchment during the late 1970s to 1990s. The impact of climatic factors and anthropogenic interventions on runoff change also differed between catchments. Our analysis concludes that the effects of human intervention in Beiluo and Jinghe catchments are slight. This is indicated by the low variation of the significant interannual relationships between runoff and precipitation and only a small decrease in runoff. In particular in Beiluo catchment, the interannual relationships between runoff and precipitation remain significant $(P<0.05)$ across the entire study period of 1961-2009. The effects of human intervention in Kuye, Tuweiand Jialu catchments are strong, as shown by the nonsignificant interannual relationships between runoff and precipitation following the significant decrease in runoff. The low year-to-year variability of runoff and the insignificant relationship with precipitation indicates continuing intensive human intervention in Wuding catchment. The high catchment-to-catchment variability of interannual relationships between runoff and precipitation and the changes in runoff may be partially attributed to the difference in the sensitivities of ecosystems to climate change.

In general, decreased amounts of runoff in different transition years were contributed by different catchments. Catchments, excluding Jinghe, contributed to the decreased runoff in the transition year of
1970. Eight catchments (HuangFu, GuShan, Kuye, TuWei, Jialu, DaLi, Qingjian and Xinshui) contributed to runoff reduction in CM in 1981. Catchments excluding Wuding, Beiluo contributed to runoff reduction in CM in 1996 (Fig. 7).

\section{Discussion}

5.1. The interactive role of climatic and anthropogenic factors in runoff change in the Loess Plateau

Our results cast doubt on the simple extrapolation of a climatic relationship with runoff in coupled human and natural systems by considering the complex and nonlinear dynamics of the human domestication of landscapes. Although variation of precipitation was the dominant reason for runoff change during the entire period of 1961-2009, human intervention was responsible for the transition points of runoff reduction. Moreover, our study found a decrease in water yield following the human-initiated runoff reduction.

For the Loess Plateau, except for the two peak stages of the establishment of tree and pasture plantations in the 1980s and 2000s, terrace construction is correlated significantly with tree and pasture construction (correlation coefficient $0.86(P<0.001)$ in the 1970s; correlation coefficient $0.54(P=0.046)$ in the $1990 \mathrm{~s})$. Terrace construction, together with tree/pasture plantation, plays an important role in regulating runoff; but our analysis did not find an impact from dam construction in the $\mathrm{CM}$.

The average size of a dam is only $0.028 \mathrm{~km}^{2}$ (Xu et al., 2004). Multiplying the average size of check dam by their total number, 32,200 given by Xu et al. (2004), we conclude that the total area covered by dams constructed in the 2000s is $902 \mathrm{~km}^{2}$ over the entire Loess Plateau, which is only $5.6 \%$ of the afforested area during the period (i.e., $16,000 \mathrm{~km}^{2}$ ). It represents $0.8 \%$ of revegetation area reported by the Yellow River Conservancy Commission in the CM (tree and grass plantations, 26,300 $\mathrm{km}^{2}$ ). Thus the effects of dam construction should not have a predominant effect on the runoff reduction in $\mathrm{CM}$. However, the impact of dam construction was more easily observed through local in situ measurements (Xu et al., 2004; Wang et al., 2015). Dams decrease the runoff coming out of a catchment because water is retained as soil moisture in dam area.

Besides the above-mentioned precipitation and human soil conservation measures, other factors may also impact runoff in the Loess Plateau, for example a statistically significant climatic drying starting from 2000 (Zhang et al., 2015). Zhang et al. (2016) suggested that the runoff decrease in the Loess Plateau in the 2000s could be attributed to climate aridity coupled with revegetation. Because both the climatic conditions and human interventions keep changing, studies on the interactive role of climatic and anthropogenic factors in runoff change in 
the Loess Plateau need long-term monitoring and transient, rather than static, analysis is highly recommended.

\subsection{Altered ecosystem services in the Loess Plateau}

Both engineering and ecological measures decrease water yield; however, they function in different ways. Sediment-trapping dams and terrace construction alter the land-surface topography and increase infiltration of precipitation (Mu et al., 2007). Revegetation increases vegetation cover and thus leads to greater evapotranspiration. The altered hydrological cycle will go beyond freshwater provisioning for human beings, since water has direct or indirect causal relationships between the human and natural needs. The construction of sedimenttrapping dams and terraces will improve water-rich land and hence improve the ES of food production in the CM (Lü et al., 2012). Revegetation will not only reduce soil erosion from hill slopes (Feng et al., 2010), but will also enhance carbon sequestration (Feng et al., 2013). According to Lü et al. (2012), water yield decreased across the entire Loess Plateau at an average rate of $10.3 \mathrm{~mm}_{\text {year }}{ }^{-1}$ during $2000-2008$; however this was accompanied by a 3.4 billion tonne increase in annual average soil retention, $12.2 \mathrm{Tg}$ increase in carbon sequestration and a 1.3 times increase in grain production. The altered ecosystem services in the 2000s are mostly related with the land-cover change after the massive afforestation of the Loess Plateau. Thus the decrease in water yield and the improvement in vegetation cover are due to the increased water demand of plantations on the water-limited Loess Plateau. The improved carbon sequestration, soil conservation and grain production follow the increased land cover. Our analysis further showed that both ecosystem services and the degree of synergy and tradeoff between them differ with different degrees of engineering and the ecological measures that were implemented in the Loess Plateau. Thus, special attention should be paid to these interactions. The corresponding transition points of runoff reduction will require further analysis of the synthesis and tradeoff between different ESs (i.e., carbon sequestration, soil conservation and grain production).

Recognizing that much of our world is now a managed environment, there is an increasing research interest in managing the ecosystem service of the provision of freshwater. Current studies have formed a theoretical framework linking ecosystem services with human activities (Fu et al., 2015). In addition, we believe that studies on the nonlinearity of changes in water resources are essential. In particular, the future climate of the water-limited Loess Plateau is expected to be warmer and drier (Lü et al., 2015). We conclude that the available water resources should be considered as the kernel for deciding on further human intervention to the landscape in this area, since water resources are important not only for raising plants and crops but also for the maintenance of human life. According to our study, a rational balance between engineering and ecological measures would be a possible solution.

\section{Conclusion}

The loess hilly area in the Loess Plateau was experiencing extensive human intervention, causing a general runoff reduction at the average rate of $-0.9 \mathrm{~mm}$ year $^{-1}(P<0.001)$ during the period of $1961-2009$. In this study, by combining moving window detection with trend analysis, we identified transition points at the years of 1970, 1981 and 1996. By combining moving window detection with partial correlation analysis, we found a weakened relationship between annual runoff and annual precipitation at the defined transition points. We concluded that human soil conservation measures (i.e., terrace construction and massive revegetation) are responsible for these transition points. Runoff reduction further caused a decrease in the ecosystem service of water provisioning in the loess hilly area.

When compared to the analysis based on a static change-point in the time series of a runoff during 1961-2009, our analysis demonstrates the nonlinearity of the dynamic water resources in a managed ecosystem.
Furthermore, the identification of different anthropogenic factors is critical as the first basic step of understanding the syntheses and tradeoffs between ecosystem services in the intensively managed Loess Plateau.

\section{Acknowledgments}

The National Natural Science Foundation of China (Grant Nos. 41390464 and 41561134016), the Chinese Academy of Sciences (Grant No. GJHZ1502), and the Major Programme of High Resolution Earth Observation System (30-Y30B13-9003-14/16-02) funded this work.

\section{References}

Agrawal, A., Lemos, M.C., 2007. A greener revolution in the making? Environmental governance in the 21st century. Environment 49, 36-45.

Carpenter, S.R., DeFries, R., Dietz, T., Mooney, H.A., Polasky, S., Reid, W.V., Scholes, R.J., 2006. Millennium ecosystem assessment: research needs. Science 314 (5797), 257-258.

Chen, J., John, R., Zhang, Y., Shao, C., Brown, D.G., Batkhishig, O., Amarjargal, A., Ouyang, Z., Dong, G., Wang, D., Qi, J., 2015. Divergences of two coupled human and natural systems on the Mongolian Plateau. Bioscience 65 (6), 559-570.

Entwisle, B., Stern, P.C., 2005. Population, Land Use, and Environment: Research Directions. The National Academies Press, Washington DC, USA

Farley, K.A., Jobbagy, E.G., Jackson, R.B., 2005. Effects of revegetation on water yield: a global synthesis with implications for policy. Glob. Chang. Biol. 11, 1565-1576.

Feng, X.M., Fu, B.J., Lu, N., Zeng, Y., Wu, B.F., 2013. How ecological restoration alters ecosystem services: an analysis of carbon sequestration in China's Loess Plateau. Sci. Rep. 3, 2846. http://dx.doi.org/10.1038/srep02846.

Feng, X.M., Sun, G., Fu, B.J., Su, C.H., Liu, Y., Lamparski, H., 2012. Regional effects of vegetation restoration on water yield across the Loess Plateau, China. Hydrol. Earth Syst. Sci. $16,2617-2628$.

Feng, X.M., Wang, Y.F., Chen, L.D., Fu, B.J., Bai, G.S., 2010. Modeling soil erosion and its response to land-use change in hilly catchments of the Chinese Loess Plateau. Geomorphology 118, 239-248.

Fu, B.J., Zhang, L.W., Xu, Z.H., Zhao, Y., Wei, Y.P., Skinner, D., 2015. Ecosystem services in changing land use. J. Soils Sediments 15 (4), 833-843.

Gao, P., Jiang, G.T., Wei, Y.P., Mu, X.M., Wang, F., Zhao, G.J., Sun, W.Y., 2015. Streamflow regimes of the Yanhe River under climate and land use change, Loess Plateau, China. Hydrol. Process. 29 (10), 2402-2413.

Hald, A., 1952. Statistical Theory With Engineering Applications. John Wiley, New York.

Li, Z., Liu, W.Z., Zhang, X.C., Zheng, F.L., 2009. Impacts of land use change and climate variability on hydrology in an agricultural catchment on the Loess Plateau of China. J. Hydrol. 377 (1-2), 35-42.

Liang, W., Bai, D., Wang, F., Fu, B., Yan, J., Wang, S., Yang, Y., Long, D., Feng, M., 2015. Quantifying the impacts of climate change and ecological restoration on streamflow changes based on a Budyko hydrological model in China's Loess Plateau. Water Resour. Res. 51, 6500-6519.

Liu, J.G., Dietz, T., Carpenter, S.R., Alberti, M., Folke, C., Moran, E., Pell, A.N., Deadman, P., Kratz, T., Lubchenco, J., Ostrom, E., Ouyang, Z., Provencher, W., Redman, C.L., Schneider, S.H., Taylor, W.W., 2007. Complexity of coupled human and natural systems. Science 317 (5844), 1513-1516.

Liu Q., McVicar, T.R., 2012. Assessing climate change induced modification of Penman potential evaporation and runoff sensitivity in a large water-limited basin. J. Hydrol. 464-465, 352-362.

Lü, Y., Fu, B.J., Feng, X.M., Zeng, Y., Liu, Y., Chang, R.Y., Sun, G., Wu, B.F., 2012. A policy-driven large scale ecological restoration: quantifying ecosystem services changes in the Loess Plateau of China. PLoS One 7 (2), e31782. http://dx.doi.org/10.1371/journal. pone.0031782.

Milano, M., Reynard, E., Köplin, N., Weingartner, R., 2015. Climatic and anthropogenic changes in western Switzerland: impacts on water stress. Sci. Total Environ. 536, $12-24$.

Millennium Ecosystem Assessment, 2005. Ecosystems and Human Well-being. USA, Washington DC

Milly, P.C.D., Dunne, K.A., Vecchia, A.V., 2005. Global pattern of trends in streamflow and water availability in a changing climate. Nature 438 (7066), 347-350.

Ministry of Water Resources, 2013. Bulletin of First National Water Census for Soil and Water Conservation, People's Republic of China.

Mu, X.M., Zhang, L., McVicar, T.R., Chille, B.S., Gau, P., 2007. Analysis of the impact of conservation measures on stream flow regime in catchments of the Loess Plateau, China. Hydrol. Process. 21 (16), 2124-2134.

Penman, H.L., 1948. Natural evaporation from open water, bare soil and grass. Proc. R. Soc. London, Ser. A 193, 120-145.

Pettitt, A.N., 1979. A non-parametric approach to the change-point problem. Appl. Stat. 28 (2), 126-135.

Piao, S.L., Nan, H.J., Huntingford, C., Ciais, P., Friedlingstein, P., Sitch, S., Peng, S.S., Ahlstrom, A., Canadell, J.G., Cong, N., Levis, S., Levy, P.E., Liu, L.L., Lomas, M.R., Mao, J.F., Myneni, R.B., Peylin, P., Poulter, B., Shi, X.Y., Yin, G.D., Viovy, N., Wang, T., Wang, X.H., Zaehle, S., Zeng, N., Zeng, Z.Z., Chen, A.P., 2014. Evidence for a weakening relationship between interannual temperature variability and northern vegetation activity. Nat. Commun. 5, 5018. http://dx.doi.org/10.1038/ncomms6018 (2014). 
Piñol, J., Àvila, A., Escarré, A., 1999. Water balance in catchments. In: Rodà, F., et al. (Eds.), Ecology of Mediterranean Evergreen Oak Forests. Springer-Verlag Press, pp. 273-282.

Rustomji, P., Zhang, X.P., Hairsine, P.B., Zhang, L., Zhao, J., 2008. River sediment load and concentration responses to changes in hydrology and catchment management in the Loess Plateau region of China. Water Resour. Res. 44. http://dx.doi.org/10.1029/ 2007WR006656 (W00 A04).

Searcy, J.K., Hardisoni, C.H., 1960. Double Mass Curves, Geological Survey Water Supply Paper 1541-B. US Geological Survey, Washington, DC

Shi, C., Dian, Z., You, L., 2002. Changes in sediment yield of the Yellow River basin of China during the Holocene. Geomorphology 46, 267-289.

Syvitski, J.P.M., Kettner, A., 2011. Sediment flux and the Anthropocene. Philos. Trans. R. Soc. London, Ser. A 369, 957-975.

Tang, Q., Oki, T., Kanae, S., Hu, H., 2008. A spatial analysis of hydro-climatic and vegetation condition trends in the Yellow River basin. Hydrol. Process. 22 (3), 451-458.

Villa, F., Voigt, B., Erickson, J.D., 2014. New perspectives in ecosystem services science as instruments to understand environmental securities. Philos. Trans. R. Soc. London, Ser. B 369, 20120286. http://dx.doi.org/10.1098/rstb.2012.0286.

Wahba, G., Wendelberger, J., 1980. Some new mathematical methods for variational objective analysis using splines and cross validation. Mon. Weather Rev. 108, 1122-1145.

Wang, H., Yang, Z., Saito, Y., Liu, J.P., Sun, X., Wang, Y., 2007. Stepwise decreases of the Huanghe (Yellow River) sediment load (1950-2005): impacts of climate change and human activities. Glob. Planet. Chang. 57, 331-354.

Wang, S., Fu, B.J., Piao, S.L., Lu, Y.H., Ciais, P., Feng, X.M., Wang, Y.F., 2015. Reduced sediment transport in the Yellow River due to anthropogenic changes. Nat. Geosci. 8, 38-41. http://dx.doi.org/10.1038/ngeo2602.

Wei, W., Chen, L.D., Zhang, H.D., Chen, J., 2015. Effect of rainfall variation and landscape change on runoff and sediment yield from a loess hilly catchment in China. Environ. Earth Sci. 73 (3), 1005-1016.

Woodward, C., Shulmeister, J., Larsen, J., Jacobsen, G.E., Zawadzki, A., 2014. The hydrological legacy of deforestation on global wetland. Science 346 (6211), 844-847.

Wu, Y.P., Liu, S.G., Sohl, T.L., Yong, C.J., 2013. Projecting the land cover change and its environmental impacts in the Cedar River basin in the Midwestern United States. Environ. Res. Lett. 8 (2), 024025. http://dx.doi.org/10.1088/1748-9326/8/2/024025.

$\mathrm{Xu}$, J., Katsigris, E., White, T.A., 2002. Implementing the natural Forest protection program and the sloping land conversion program: Lessons and policy implications. China
Council for International Cooperation on environment and development. Western China Forests and Grassland Taskforce, Beijing, China (in Chinese).

Xu, X.Z., Zhang, H.W., Zhang, O.Y., 2004. Development of check-dam systems in gullies on the Loess Plateau, China. Environ. Sci. Pol. 7, 79-86.

Yuan, N.M., Fu, Z.T., Zhang, H., Piao, L., Xoplaki, E., Luterbacher, J., 2015. Detrended partialcross-correlation analysis: a new method for analyzing correlations in complex system. Sci. Rep. 5, 8143. http://dx.doi.org/10.1038/srep08143.

Zhang, B., He, C., Burnham, M., Zhang, L., 2016. Evaluating the coupling effects of climate aridity and vegetation restoration on soil erosion over the Loess Plateau in China. Sci. Total Environ. 539, 436-449.

Zhang, B., Zhao, X., Jin, J., Wu, P., 2015. Development and evaluation of a physically based Multiscalar drought index: the standardized moisture anomaly index. J. Geophys. Res. Atmos. 120, 11575-11588.

Zhang, X.P., Zhang, L., Zhao, J., Rustomji, P., Hairsine, P., 2008. Responses of streamflow to changes in climate and land use/cover in the Loess Plateau, China. Water Resour. Res 44. http://dx.doi.org/10.1029/2007WR006711 (W00 A07).

Zhao, G.J., Tian, P., Mu, X.M., Jiao, J.Y., Wang, F., Gao, P., 2014. Quantifying the impact of climate variability and human activities on streamflow in the middle reaches of the Yellow River basin, China. J. Hydrol. 519, 387-398.

Zhao, X., Liang, S.L., Liu, S.H., Yuan, W.P., Xiao, Z.Q., Liu, Q., Cheng, J., Zhang, X.T., Tang, H.R. Zhang, X., Liu, Q., Zhou, G.Q., Xu, S., Yu, K., 2013. The global land surface satellite (GLASS) remote sensing data processing system and products. Remote Sens. 5 (5), 2436-2450.

Zhou, G.Y., Wei, X.H., Chen, X.Z., Zhou, P., Liu, X.D., Xiao, Y., Sun, G., Scott, D.F., Zhou, S.Y.D., Han, L.S., Su, Y.X., 2015. Global pattern for the effect of climate and land cover on water yield. Nat. Commun. 6, 5918. http://dx.doi.org/10.1038/ncomms6918.

Zhou, S.T., Miller, A.J., 2000. A partial correlation analysis of the stratospheric ozone response to 27-day solar UV variations with temperature effect removed. J. Geophys. Res. 105 (D4), 4491-4500.

Zuo, D.P., Xu, Z.X., Yao, W.Y., Jin, S.Y., Xiao, P.Q., Ran, D.C., 2016. Assessing the effects of changes in land use and climate on runoff and sediment yields from a watershed in the Loess Plateau of China. Sci. Total Environ. 544, 238-250. 